\title{
Current Prevalence and Determinants of Anaemia in Under-five Children in Rural Bangladesh: A Cross Sectional Study
}

\author{
Mohammad Moniruzzaman Mollah ${ }^{1,7,}$, Ashik Mosaddik ${ }^{2}$, Asgor Hossain ${ }^{3}$, Andrew Asim Roy ${ }^{4}$, \\ Sultana Naznin ${ }^{5}$, Mohammad Shukur Ali ${ }^{6}$, Parvez Hassan ${ }^{7}$ \\ ${ }^{1}$ Department of Paediatrics, Shaheed Ziaur Rahman Medical College, Bogura, Bangladesh \\ ${ }^{2}$ Department of Pharmacy, University of Rajshahi, Rajshahi, Bangladesh \\ ${ }^{3}$ Department of Paediatrics, Rajshahi Medical College, Rajshahi, Bangladesh \\ ${ }^{4}$ Faculty, Department of Medicine and Biomedical Sciences, Maastricht University, Maastricht, the Netherlands \\ ${ }^{5}$ Department of Gynae and Obs, IBMCH, Rajshahi, Bangladesh \\ ${ }^{6}$ Department of English, University of Development Alternative (UODA), Dhaka, Bangladesh \\ ${ }^{7}$ Institute of Biological Sciences (IBSc), Rajshahi University, Rajshahi, Bangladesh
}

Email address:

dr_moniruzzaman@yahoo.com (M. M. Mollah)

*Corresponding author

\section{To cite this article:}

Mohammad Moniruzzaman Mollah, Ashik Mosaddik, Asgor Hossain, Andrew Asim Roy, Sultana Naznin, Mohammad Shukur Ali, Parvez Hassan. Current Prevalence and Determinants of Anaemia in Under-five Children in Rural Bangladesh: A Cross Sectional Study. American Journal of Pediatrics. Vol. 7, No. 3, 2021, pp. 137-144. doi: 10.11648/j.ajp.20210703.19

Received: July 3, 2021; Accepted: July 24, 2021; Published: August 2, 2021

\begin{abstract}
Background: Anaemia and its association with low physical and cognitive development in under-five children remain a common public health burden in developing countries including Bangladesh. Childhood anemia is significantly associated with age, rural residence, infant and young child feeding (IYCF) practices, infectious disease, maternal illiteracy etc. We have studied to identify the current prevalence and to explore associated socio-demographic, health, and nutritional factors of anaemia in under-five children of rural Bangladesh. Methods and Materials: A cross-sectional study was conducted at five remote northern districts of Bangladesh involving rural children aged $6-<60$ months. We used an interviewer-administered questionnaire for data collection. Potential study subjects were approached conveniently at selected rural health centres. The chi-squared test was the main statistical model to identify the association between explanatory variables and anaemia. A p-value $<0.05$ was considered significant. Results: The overall prevalence of anaemia $(\mathrm{N}=258)$ was $61.23 \%$ with mild, moderate and severe anaemia of $28.29 \%$, $28.68 \%$ and $4.26 \%$ respectively. The prevalence of anaemia was the highest $(72 \%)$ in the age group $6-24$ months, which were followed by $63 \%$ in $>24-36$ months and $44.3 \%$ in $>36-<60$ months categories. The following explanatory variables showed statistically significant association with high anaemia: younger-age $(\mathrm{p}=<0.001)$, low family income, and maternal education $(p=<0.001)$, exclusive versus non-exclusive breastfeeding $(p=0.02)$, and timely versus delayed or early weaning $(p=<0.001)$. Non-consumption of animal proteins, fruits and green leafy vegetables were also significantly linked to high anaemia prevalence $(p=0.001)$. Further, underweight, stunting, and wasting were significantly related to anaemia $(p=0.02,0.006$, and 0.001 respectively). Conclusion: The prevalence of anaemia in under-five children of rural Bangladesh remains noticeably high. Age, maternal education, family income, consumption of animal protein, green leafy vegetables, and fruits along with underweight, stunting and wasting are inversely related to anaemia prevalence. Exclusive breastfeeding and timely weaning may reduce the risk of anaemia.
\end{abstract}

Keywords: Anaemia Prevalence, Childhood Anaemia, Determinants, Iron Deficiency, Under-five Children 


\section{Introduction}

Anaemia is one of the major public health burdens in the world particularly for young and preschool children. Globally, nearly $50 \%$ of under-five children are suffering from anaemia [1]. Anaemia is linked to a wide range of childhood disorders such as cognitive development, low scholastic performance, insufficient physical growth and behavioral development and low immunity among others. Because of these adverse health and socio-economic consequences, anaemia prevalence of more than $40 \%$ in any population is identified as a serious public health problem [2]. Anemia is the second leading nutritional cause of diverse disorders with adverse effects on socioeconomic development [3]. Anemia is significantly associated with fetal low birth weight (LBW). sex, age, rural residence, infant and young child feeding (IYCF) practices, infectious disease (e.g., malaria, tuberculosis, intestinal parasitic infestation), under-nutrition (e.g., stunting, wasting, and underweight), poor socioeconomic status, household food insecurity, duration of lactation, poor dietary iron intake, maternal illiteracy and maternal anemia are reported as predictors of anaemia [4-7].

According to recent information from the South-Asian region, nearly $79 \%$ Indian children aged 6-35 months suffer from anaemia with a rural predominance $[8,9]$ Anaemia still remains as one of the major cause of mortality and morbidity in many developing countries including Bangladesh [1]. In Bangladesh, several studies have reported that anemia among the under-five children is a considerable public health problem. Bangladesh Demographic Health Survey (BDHS) 2011 reported $51 \%$ anaemia prevalence in the total population [10]. An anemia prevalence of $33.1 \%$ was reported by National Micronutrient Status Survey in pre-school children with rural and urban prevalence of $37.0 \%$ and $22.8 \%$ respectively. Several studies found that the prevalence of anemia was higher in children aged $<3$ years among under-five children [11].

Timely starting of complementary feeding at age 6 months is an utmost importance for infant growth and nutrition. In Bangladesh, nearly $62 \%$ of children start delayed complementary feeding [10]. The suboptimal infant and young child feeding (IYCF) practices along with early or delayed weaning was found associated with high level nutritional anaemia [10]. Iron deficiency is the most common cause of nutritional anemia in young children [11, 12]. Folic acid and vitamin B12 deficiency are also not uncommon causes of nutritional anaemia [11]. Prevalence of iron deficiency anemia varies across countries with four-times higher in developing than in developed countries [5]. Empirically, iron deficiency anemia increases risk of morbidity and mortality from infectious disease $[4,9,13]$. To eliminate childhood nutritional anemia, particularly iron deficiency anaemia is a public-health priority and reportedly the most common cause of anaemia among under-five children with high prevalence among rural dwellers who occupy nearly $68 \%$ of the total population of Bangladesh [14].
However, there are very few studies and consistent data on the current prevalence of anaemia and its determinants in under-five children in rural Bangladesh to fight anaemia. Hence, we aim for such a study.

\section{Objective}

This study is aimed (i) to identify the current prevalence of anemia among under-five children in rural Bangladesh, and (ii) to assess if there are any associations of anemia with socio-demographic, health, food and nutritional factors in this target population.

\section{Methods}

A cross-sectional study was conducted in the rural areas of northern Bangladesh. Eleven Upazillas (sub-district) of five districts were selected purposively as the study settings (Table 1). The study districts and Upazilla represent typical and nearly homogenous socioeconomic, demographic and cultural contexts of rural Bangladesh. Nearly $85 \%$ population of the sample districts were rural residents. [10]

Table 1. Sample districts with corresponding sample upazillas.

\begin{tabular}{ll}
\hline District & Corresponding upazilla* \\
\hline Joypurhat & Panchbibi, Jopurhat Sador, Ketlal, Kalai, Akkelpur \\
Dinajpur & Hakimpur, Ghoraghat \\
Naugaon & Dhamuirhat, Bodolgachi \\
Gaibandha & Gobindogong \\
Bogura & Sibgong \\
\hline
\end{tabular}

Under-five children aged $6-<60$ months were the target population. A sample size of 325 was calculated using Cockranch's formula (where N=Sample size, $\mathrm{z}=1.96$ (95\% confidence level), $p=33 \%$ estimated prevalence of anemia in under-five population basing on available information, and $\mathrm{e}=0.05$ at $5 \%$ margin of error). Rural children of aged $6-<60$ months whose guardians provided written consent were included in the study. Children who were living in urban, i.e., municipality area, in need of emergency care and hospitalization, and/or having history of blood transfusion within last three months from the date of data collection were not included. A questionnaire was prepared involving three researchers; any contradictions were solved by discussion. A piloting was conducted by the Principal Investigator (PI) involving parents of ten patients for testing mainly the qualitative variables and to develop skills of the PI. The questionnaire was finalized with minimum changes and contained the following four main section: particulars of the children, quantitative domains: nutritional anthropometry (height/length, weight) and laboratory reports (complete hemogram, ferritin level, $\mathrm{Hb}$ electrophoresis, Zinc level, Folate and vitamin $\mathrm{B}_{12}$ assay); qualitative domains: sociodemographic variables (maternal education, income and occupation of household head, number of children, consanguinity), nutrition (breast feeding, IYCF, stunting, wasting, underweight, consumption of protein, fruits, 
vegetable) and health (maturity at birth and birth size, and history of recent infection.

Data was collected consecutively from purposively selected 22 rural health facilities and EPI outreach centers in the study Upazilas. At first the PI (a child health specialist experienced in primary research), approached the under-five children presented at the out-patient department of the selected health facilities. The objectives of the study and the reason of collecting blood were explained. Parents/guardians were assured free of cost blood tests which would solely be used for the study. They were also assured access to the study findings with a guideline for the next treatment options, but without financial benefits. Following an initial face-to-face interview for collecting qualitative data, parents with eligible child were sent to the assigned laboratory. Five millilitre $(\mathrm{ml})$ venous blood was drawn using a sterile syringe $(3 \mathrm{ml}$ blood were preserved into ethylene ediamine tetraacetic acid (EDTA) vial and the next $2 \mathrm{ml}$ into another test-tube for separating serum). The EDTA blood was analyzed on the same day with an 'Automated
Hematology Analyzer' (Nihon Kohden, Tokyo, Japan) for a Complete Blood Count (CBC; i.e., haemoglobin percentage, hematocrit), Red cell indices (i.e., $\mathrm{MCV}, \mathrm{MCH}, \mathrm{MCHC}, \mathrm{RWD}$ ), total count of white blood cell (WBC), differential count of WBC and total platelet count. The degree of anaemia was classified into three categories on the basis of hemoglobin level as defined by the World Health Organization. [3] Accordingly, mild anaemia was considered with a $\mathrm{Hb} \%$ of $10.00-10.90$ $\mathrm{gm} / \mathrm{dl}$, which for moderate and severe anaemia were 7.00 - 9.90 $\mathrm{gm} / \mathrm{dl}$ and $<7.00 \mathrm{gm} / \mathrm{dl}$ respectively.

Basing on mean corpuscular volume (MCV), anemia were further classified as normocytic (MCV 80-96 fl), microcytic ( $\mathrm{MCV}<80 \mathrm{fl}$ ), and macrocytic (MCV $>96 \mathrm{fl})$. Serum Ferritin and/or Hb-electrophoresis were done in children with microcytic hypochromic anemia; whereas macrocytic anemias were evaluated assaying Vitamin $\mathrm{B}_{12}$ and folic acid levels; and normocytic normochromic anaemia were investigated with Serum Zinc level to reach the etiological pattern of anemia (Figure 1).

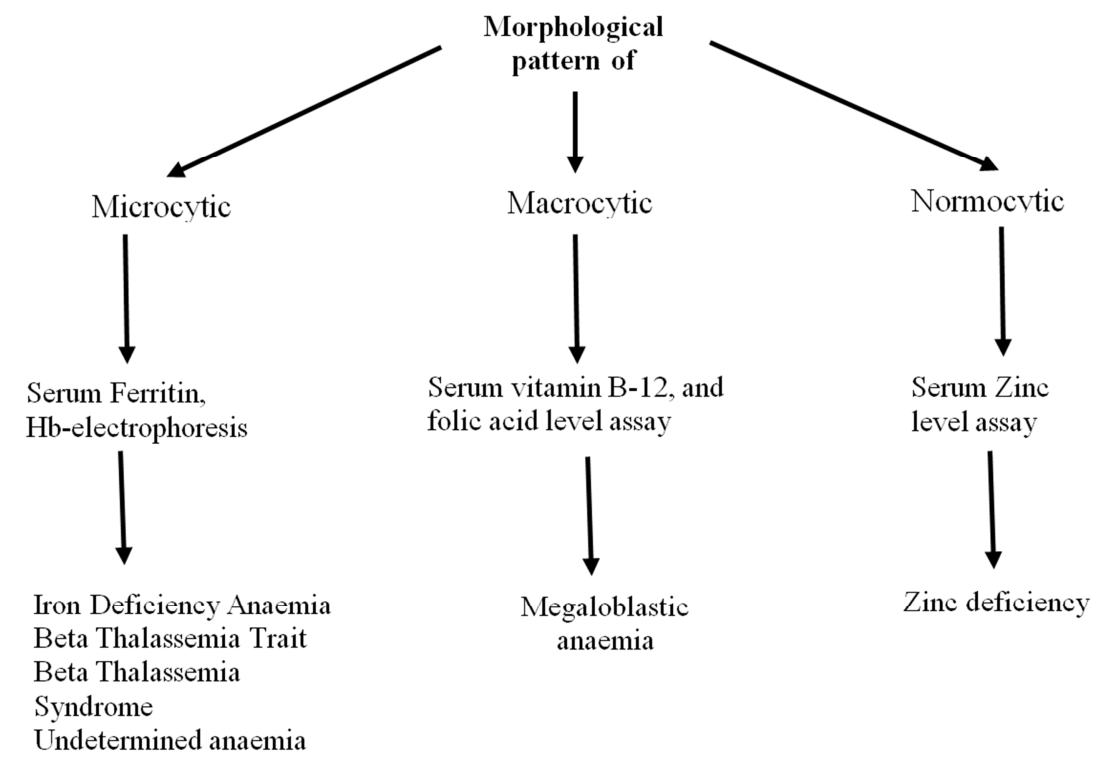

Figure 1. Laboratory diagnostic algorithm of anaemia.

Ethical clearance was obtained from the Institutional Animal, Medical Ethics, Bio-safety and Bio-security Committee (IAMEBBC) of the Institute of Biological Sciences, Rajshahi University (memo no: 83/320/IAMEBBC/IBSC, date: 27 August 2017). Informed written consents were taken from parents of the sample children. Data were computed and analyzed using SPSS (version 23.0). Univariate analysis and chai-squared tests were the main models to identify the prevalence of anaemia and to assess any association between the independent variables and anaemia. A p-value $<0.05$ was considered as significant.

\section{Results}

Because of time and resource constraints, it was possible to collect data from a total of 258 target children from a total of eleven sample upazillas of five districts (Table 2). $60 \%$ of the total study subjects were male and the rest were female. Overall prevalence of anaemia was $61.23 \%(\mathrm{~N}=258)$. Of the total male children $(n=154)$, nearly $65 \%$ were anaemic and that was $56 \%$ in female children $(n=104)$.

Table 2. Distribution of sample children across the sample districts.

\begin{tabular}{ll}
\hline District (No. of Upazilla) & Sampled children (\% of total enrolled) \\
\hline Joypurhat (5) & $90(34.88 \%)$ \\
Dinajpur (2) & $59(22.86 \%)$ \\
Gaibandha (1) & $38(14.73 \%)$ \\
Naugaon (2) & $41(15.90 \%)$ \\
Bogura (1) & $30(11.63 \%)$ \\
\hline
\end{tabular}

The gender difference in prevalence of anaemia was not significant $(\mathrm{p}=0.088)$. The majority $(50 \%)$ children was in age group 6-24 months, which was followed by $>36-60$ months (34\%) and $>24-36$ months $(16 \%)$. The prevalence of anaemia was $72 \%$, the highest, in $6-24$ months group, which was 
followed by $63 \%$ in age group $>24-36$ months and $44.3 \%$ in >36-60 months with a statistically significant association between age categories and anaemia $(\mathrm{p}=<0.001)$. Among the children, Muslims were from the majority $88.8 \%$ and the rest were from Hindu and indigenous population. The prevalence of anaemia was the highest $(63.3 \%)$ in Muslims, which was followed by $57.1 \%$ in indigenous group and $40.9 \%$ in Hindus. The association between religion and anaemia was not significant $(\mathrm{p}=0.12)$ (Table 2$)$.

Table 3. Socio-demographic characteristics of the participant children in relation to anaemia.

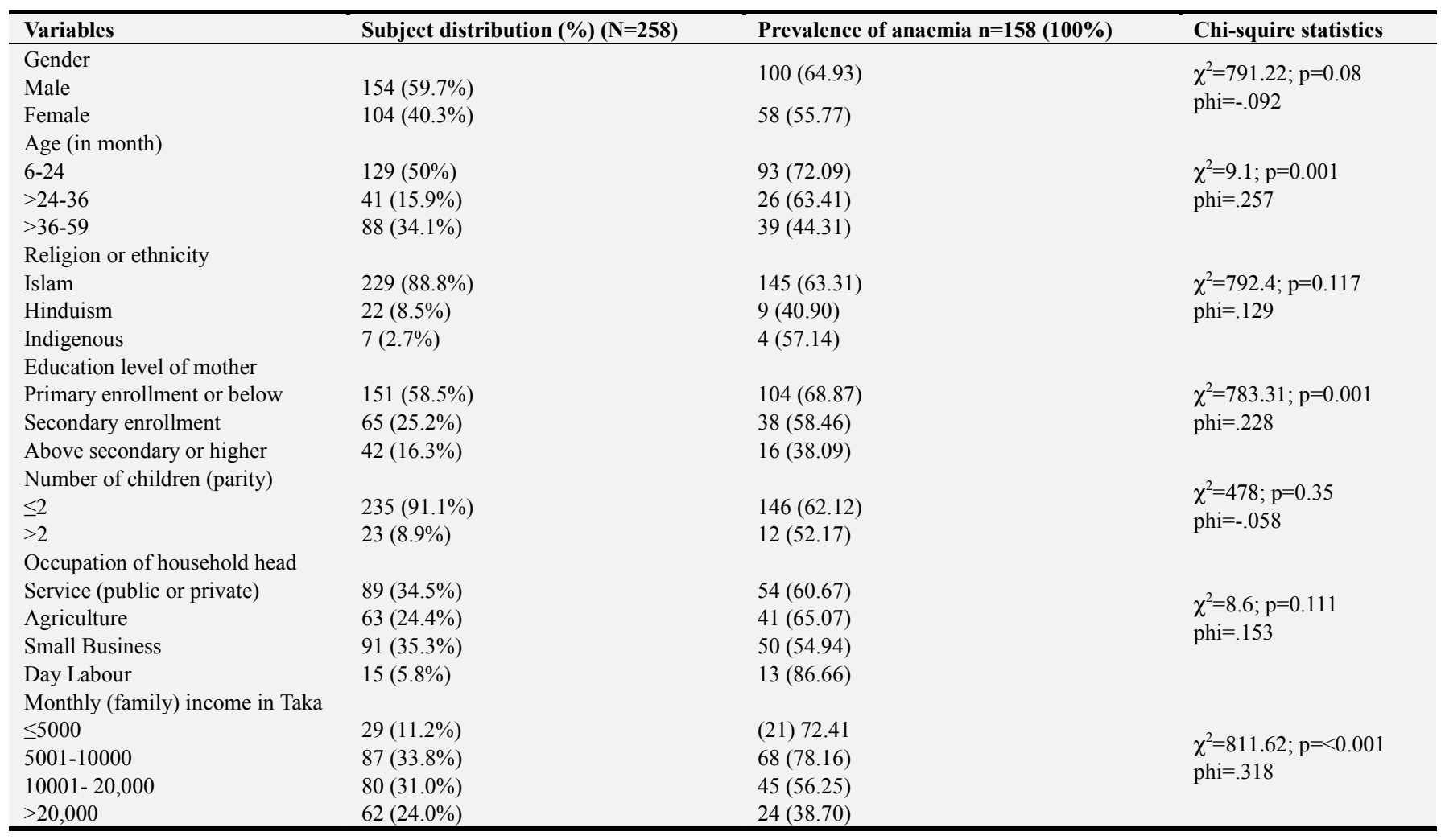

Table 4. Nutrition and food related factors associated with the prevalence of anaemia $(n=258)$.

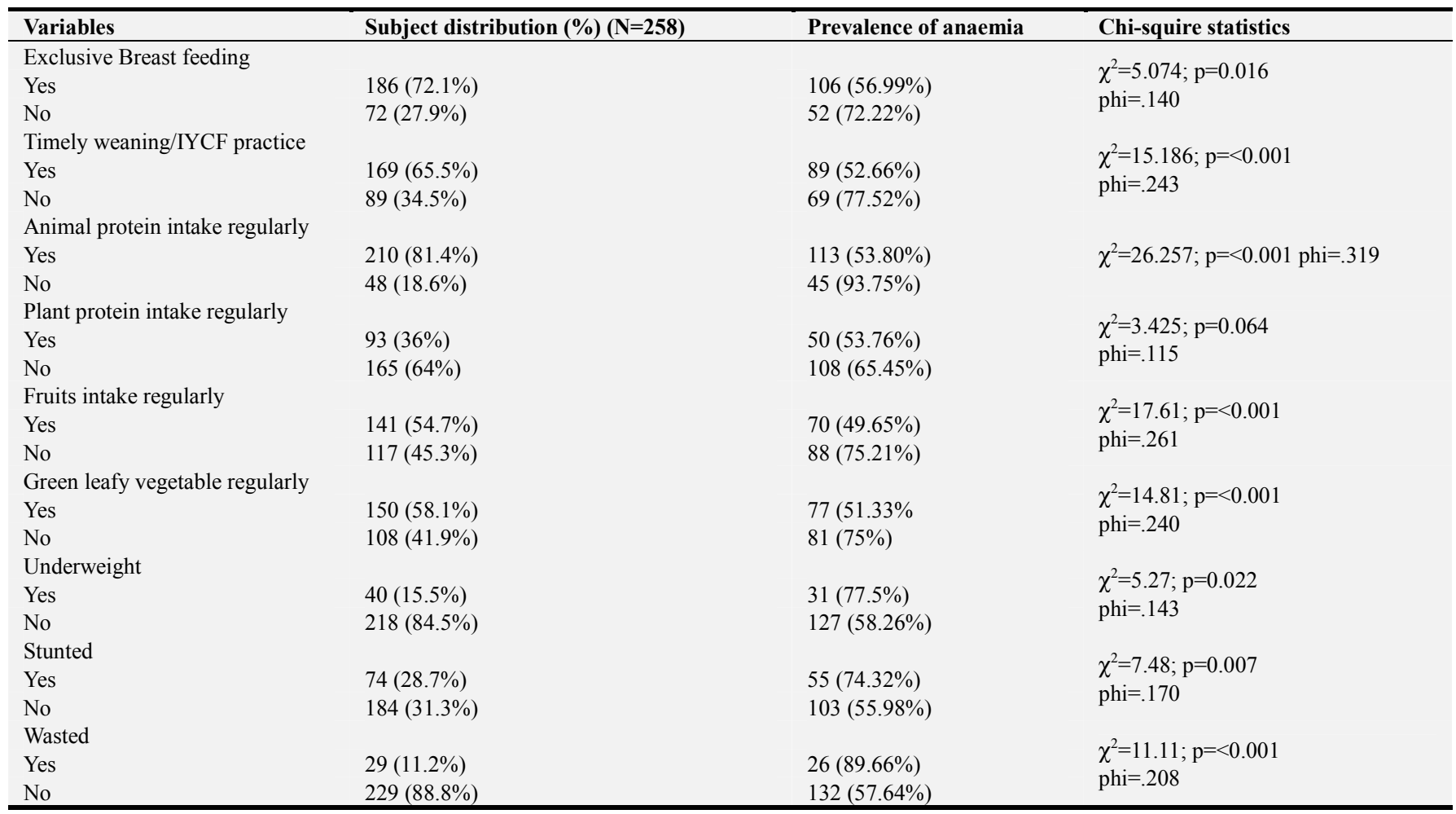


Parity (i.e., mothers with $\leq 2$ children $(91.1 \%)$ versus $>2$ children $(8.9 \%))$ was found not significantly associated with anaemia $(p=0.23)$. The distribution of small business and service were nearly equal of the children's family heads' occupation, $35.5 \%$ and $34.5 \%$ respectively and that the rest $24.4 \%$ and $5.8 \%$ were farming and day labour. Prevalence of anaemia in children belong to the day labour families was noticeably the highest (nearly $87 \%$ ), which among the children in the other three family occupation groups were nearly equal ranging from $55 \%$ in small business family to $65 \%$ in farmer family. There was no significant association between anaemia and family occupations $(p=0.11)$.

Among four categories of monthly family income, distributions of children were nearly equal in the middle two family income groups (i.e., $33.8 \%$ and $31 \%$ in 5,001-10,000 Taka (the Bangladesh currency) and 10,001- 20,000 Taka groups respectively). Notably, children of the lowest two family income groups had nearly equally the highest prevalence of anaemia; $78 \%$ and $72 \%$ in 5,001-10,000 Taka and $\leq 5,000$ Taka groups respectively (Table 1). Anaemia was found significantly associated with monthly family income $(p=<0.001)$ (Table 1). The majority, $58.5 \%$ of the total mothers' education level was below primary level. Maternal education was found significantly associated with children's anaemia $(\mathrm{p}=0.001)$ (Table 3$)$.

Exclusive breast feeding children had nearly $18 \%$ lower anaemia prevalence than non-exclusive breast feeding group and the difference was statistically significant $(p=0.02)$. Delayed or early weaning-practiced children had nearly $25 \%$ higher prevalence of anaemia than their properly weaning counterpart with a statistically significant difference $(p=<0.001)$. Non-consumption of animal protein group were found almost 2 times higher anaemia prevalence than animal protein consumption group, which was statistically significant $(\mathrm{p}=0.001)$. Plant protein (pulses) intake group had nearly $10 \%$ lower anaemia prevalence than non-consumption group, which was not significant $(\mathrm{p}=0.064)$. Children with regular fruits intake had significantly lower prevalence of anaemia by $26 \%$ than non-consumption group $(\mathrm{p}=0.001)$. Children with regular intake of green leafy vegetables also had nearly $26 \%$ lower anaemia prevalence than in non-consumption group with a statistically significant difference $(\mathrm{p}=0.001)$. Underweight children had 1.5 times higher prevalence of anaemia than their normal counterpart with a significant difference $(\mathrm{p}=0.022)$. Stunted children were found $20 \%$ higher and significant risk of developing anaemia than their counterpart $(\mathrm{p}=0.006)$. Acute under-nourished children had nearly twice higher vulnerability of developing anaemia than normal children with a significant difference $(\mathrm{p}=0.001)$ (Table 4).

Parents' consanguinity status showed no significant difference in childhood anaemia $(p=0.373)$. Pre-term children had nearly 4.5 times and 9 times higher anaemia prevalence than term and post-term babies respectively although the differences were not significant $(p=0.153)$. Birth size of babies (normal/small/large) had no significant influence on the prevalence of anaemia $(\mathrm{p}=0.69)$. Children suffering from chronic illness or recent illness had $23 \%$ higher anaemia prevalence than apparently healthy children, which was statistically significant $(\mathrm{p}=0.001)$ (Table 5).

Table 5. Association of key health and social factors to anaemia $(N=258)$.

\begin{tabular}{llll}
\hline Variables & Distribution of subjects (\%) (N=258) & Prevalence of anaemia (\%) & Chi-squire statistics \\
\hline $\begin{array}{l}\text { Consanguinity of parents } \\
\text { Yes }\end{array}$ & $39(15.1 \%)$ & $21(53.84 \%)$ & $\chi^{2}=1.058 ; \mathrm{p}=.373$ \\
No & $219(84.9 \%)$ & $137(62.55 \%)$ & Phi=.064 \\
Maturity level at birth & $201(77.91 \%)$ & $12(5.79 \%)$ & $\chi^{2}=3.758 ; \mathrm{p}=0.153$ \\
Full term & $45(17.44 \%)$ & $32(71.11 \%)$ & Phi $=.121$ \\
Pre-term & $12(04.65 \%)$ & $5(41.67 \%)$ & \\
Post-term & & & $\chi^{2}=0.724 ; \mathrm{p}=0.69$ \\
Size of baby at birth & $148(57.4 \%)$ & $5(62.12 \%)$ & $\mathrm{Phi}=.054$ \\
Normal & $50(19.4 \%)$ & $32(64.00 \%)$ & \\
Small & $60(23.2)$ & $34(56.66 \%)$ & $\chi^{2}=12.867 ; \mathrm{p}=0.001$ \\
Large & & $73(75.25 \%)$ & $\mathrm{Phi}=.223$ \\
Chronic illness or recent illness & $97(37.6 \%)$ & $85(52.79 \%)$ & \\
Yes & $161(62.4 \%)$ & & \\
No &
\end{tabular}

Among the anaemic children $(\mathrm{n}=158)$, mild $(\mathrm{Hb} \% 10-<11$ $\mathrm{gm} / \mathrm{dl})$ and moderate $(\mathrm{Hb} \% \mathrm{7}-<10 \mathrm{gm} / \mathrm{dl})$ degree of anaemia were nearly equally distributed $46.2 \%$ and $47 \%$ respectively, whereas severe anaemia $(\mathrm{Hb} \%<7 \mathrm{gm} / \mathrm{dl})$ was only $7 \%$.

\section{Discussion}

The study was undertaken to assess the current prevalence of anemia and its association with socio-demographic, health and nutritional factors in under-five children in rural Bangladesh.

The overall prevalence of anaemia $(\mathrm{N}=258)$ was $61.23 \%$ with proportion of mild, moderate and severe anaemia of $28.29 \%, 28.68 \%$ and $4.26 \%$ respectively. High prevalence of anaemia was found in some other studies in India, Tanzania, Kenya, and South Africa where the prevalence of anaemia was observed between $(69 \%$ - 79\%) in under-five children [18-20, $29]$. The prevalence of severe anaemia $(4.26 \%)$ was lower 
than in similar settings; for example, Muoneke et al [15], reported a prevalence of severe anaemia of $9.7 \%$ in Nigerian under-five children. Nearly consistent trends of mild, moderate and severe anaemia and associated factors in under-five children of this study were found in a study of Simbauranga et al at Tanzania [16]. In their study, the mild, moderate and severe anaemia were found $16.5 \%, 33 \%$ and $27.7 \%$ respectively. In a study in India, the overall prevalence of anaemia in under-five children was found $69.5 \%$ with percentage of mild moderate and severe anaemia were $26.2 \%$, $40.4 \%, 2.9 \%$ respectively [30] which is nearly consistent with our findings.

Mild and moderate anaemia in the total sample accounted nearly equally, $30 \%$ each, may be due to nutritional deficiencies and socio-demography related factors in rural Bangladesh. We found no association between gender and anaemia. Age is a significant factor of anaemia in under-five children with the highest prevalence $(73 \%)$ in $<24$ months age group than their older counterparts. These findings is consistent with the study findings of Goswmai and Das and the authors mentioned that high demand for nutrients to support the rapid body growth of the children at this age against a low supply might be the key underlying factor [17]. We also found that increasing trends of anaemia up to 2 years and then decreasing after 2 years may be relating to the children's ability to eat varieties of foods. This finding is consistent with the study of Gebreweld et al [18]. We found no significant link of ethnicity, religion or consanguinity to childhood anaemia which contradicts the findings of Goswmai and Das [17]. In this Indian study among under-five children, the authors found significant difference in religion and all types of anaemia prevalence (severe, moderate, and mild) were higher among children of Hindu families than other religions. We found that higher the mother's level of education lower the anaemia prevalence in children. Children of mothers with higher/above HSC education level had nearly two times lower risk of developing anaemia than that in below HSC level mothers. This finding is agreed with the studies of Kuziga et al. [19]. And Leite et al [20]. We found that neither occupation nor parity is significantly linked to childhood anaemia. However, family income is a significant factor with an inverse relationship between income and prevalence of childhood anaemia. The similar observations were also noted in some previous studies [20-22]. This is may be due to the fact that higher income is linked to good maternal education and better nutritional protection to children.

Both non-exclusive breast feeding and delayed/early weaning were found significant factors of developing anaemia in children. Oppositely, EBF, timely weaning, regular consumption of animal protein, green leafy vegetables and locally available fruits were found protective to childhood anaemia. These findings are consistent with the study of Kejo et al [23]. Stunted, underweight and wasted children were found more anaemic, which is consistent with the study of Kisiangani et al [24]. Children with chronic illness and recent illness were nearly 1.5 time high risk of developing anaemia which is also comply with the findings of Kumari et al. [25]
However, it is not known if those disorders are causing anaemia or vice versa although synergistic effects on each other are well-known.

\section{Limitations and Strengths}

Because of time and resource limits, the sample size was smaller than expected. The study was confined in northern Bangladesh. However, in nearly a homogenous rural context of the country, this study finding is claimed as a reflection of the childhood anaemia scenario of rural Bangladesh. In regard to the associated factors of anaemia, only univariant analyses were done, but the variants did not put together in a regressive model to identify the potential predictors.

\section{Conclusion}

Prevalence of anaemia in under-five children of rural Bangladesh remains noticeably high. Age, maternal education, family income, consumption of animal protein, green leafy vegetables, and fruits along with underweight, stunting and wasting are inversely related to anaemia prevalence. Exclusive breast feeding, timely weaning and special care before the age of 3 years may reduce risk of anaemia. In addition, chronic and recent illnesses increase susceptibility to anaemia development. To explore the potential determinants of anaemia in early childhood, large sample size covering all region and multivariate analysis are needed and recommended.

\section{List of Abbreviation}

$\begin{array}{ll}\text { BDHS: } & \text { Bangladesh Demographic Health Survey } \\ \text { CBC: } & \text { Complete Blood Count } \\ \text { LBW: } & \text { low birth weight } \\ \text { EDTA: } & \text { Ethylene-Diamine-Tetraacetic-Acid } \\ \text { EPI: } & \text { Expanded Programme on Immunization } \\ \text { Hb: } & \text { Hemoglobin } \\ \text { HKI: } & \text { Helen Keller International } \\ \text { HIV: } & \text { Human Immunodeficiency Virus } \\ \text { ICDDR, B: } & \text { International Centre for Diarrheal Disease } \\ & \text { Research, Bangladesh } \\ \text { IDA: } & \text { Iron Deficiency Anaemia } \\ \text { IPHN: } & \text { Institute of Public Health Nutrition } \\ \text { IYCF: } & \text { Infant and Young Child Feeding } \\ \text { MCH: } & \text { Mean corpuscular hemoglobin } \\ \text { MCHC: } & \text { Mean corpuscular hemoglobin concentration } \\ \text { MCV: } & \text { Mean corpuscular volume } \\ \text { ORC: } & \text { Out Reach Centre } \\ \text { PreSAC: } & \text { Pre-school aged children } \\ \text { RBC: } & \text { Red Blood Cell } \\ \text { RDW: } & \text { Red Cell distribution Width } \\ \text { UNICEF: } & \text { United Nations International Children's } \\ \text { WHO: } & \text { Emergency Fund } \\ \text { UHC: } & \text { World Health Organization. } \\ \text { SAC: } & \text { School aged children }\end{array}$




\section{Declarations}

\section{Ethics Approval}

Ethical clearance was obtained from the Institutional Animal, Medical Ethics, Bio-safety and Bio-security Committee (IAMEBBC) of the Institute of Biological Sciences, Rajshahi University (memo no: 83/320/IAMEBBC/IBSC, date: 27 August 2017). Informed written consent were taken from the attending guardian of enrolled children.

\section{Availability of Data and Materials}

Data of this study will be made available from the corresponding author on rational request.

\section{Competing Interests}

All authors declare that they have no competing interests.

\section{Funding}

The research was funded by the Institute of Biological Sciences, Rajshahi University, Rajshahi, Bangladesh.

\section{Acknowledgements}

Authors of the paper acknowledge and offer thanks to the Institute of Biological Sciences, Rajshahi University for providing resourceful environment for conducting the research. Also the cooperation of the expert laboratory staff is highly appreciated.

\section{References}

[1] Khan JR, Awan N, Misu F. Determinants of anemia among 6-59 months aged children in Bangladesh: Evidence from nationally representative data. BMC Pediatr. 2016; 16 (1): 1-13. doi: 10.1186/s12887-015-0536-z.

[2] World Health Organization. Iron Deficiency Anaemia: Assessment, Prevention, and Control A Guide for Programme Managers. 2001; Vol 314.

[3] World Health Organization. Worldwide prevalence of anaemia, WHO Vitamin and Mineral Nutrition Information System, 1993-2005. 2009. doi: 10.1017/S1368980008002401.

[4] Haas JD, Brownlie IV T. Iron deficiency and reduced work capacity: A critical review of the research to determine a causal relationship. J Nutr. 2001; 131 (2 SUPPL. 2): 676-690. doi: $10.1093 / \mathrm{jn} / 131.2 .676 \mathrm{~s}$.

[5] Villalpando S, Shamah-levy T, Sc B, Ramírez-silva CI, Mejía-rodríguez F, Rivera JA. Prevalence of anemia in children 1 to 12 years of age. Results from a nationwide probabilistic survey in Mexico. salud pública méxico /. 2003; 45 (1).

[6] Shet A, Mehta S, Rajagopalan N, et al. Anemia and growth failure among HIV-infected children in India: A retrospective analysis. BMC Pediatr. 2009; 9: 1-9. doi: 10.1186/1471-2431-9-37.

[7] S. Akers A, Howard D, Ford J. Distinguishing iron deficiency anaemia from thalassemia trait in clinical obstetric practice. J Pregnancy Reprod. 2018; 2 (1): 1-6. doi: 10.15761/jpr.1000125.

[8] USAID. Overview of the Nutrition Situation in Four Countries in South and Central Asia.; 2014.

[9] Pasricha SR, Black J, Muthayya S, et al. Determinants of anemia among young children in rural India. Pediatrics. 2010; 126 (1). doi: 10.1542/peds.2009-3108.

[10] National Institute of Population Research and Training. BANGLADESH BANGLADESH AND HEALTH SURVEY 2014.; 2014.

[11] International Centre for Diarrhoeal Disease Research Bangladesh. National Micronutrients Status Survey 2011-12: Final Report.; 2013. https://static1.squarespace.com/static/56424f6ce4b0552eb7fdc 4e8/t/57490d3159827e39bd4d2314/1464405328062/Banglade sh_NMS_final_report_2011-12.pdf.

[12] Gamit M, Talwelkar H. Survey of different types of anemia. Int J Med Sci Public Heal. 2017; 6 (3): 1. doi: 10.5455/ijmsph.2017.0851807092016.

[13] Oppenheimer SJ. Iron-deficiency anemia: reexamining the nature and magnitude of the public health problem. J Nutr. 2001; 131: 616-635.

[14] Institute of Public Health Nutrition. Institute of Public Health Nutrition Directorate General of Health Services Ministry of Health and Family Welfare Government of the People's Republic of Bangladesh.; 2015. http://iphn.dghs.gov.bd/wp-content/uploads/2016/01/NMDCS.pdf.

[15] Muoneke VU, Chidilbekwe R. Prevalence and Aetiology of Severe Anaemia in Under-5 Children in Abakaliki South Eastern Nigeria. Pediatr Ther. 2011; 01 (03): 3-7. doi: 10.4172/2161-0665.1000107.

[16] Simbauranga RH, Kamugisha E, Hokororo A, Kidenya BR, Makani J. Prevalence and factors associated with severe anaemia amongst under-five children hospitalized at Bugando Medical Centre, Mwanza, Tanzania. BMC Hematol. 2015; 15 (1). doi: 10.1186/s12878-015-0033-5.

[17] Goswmai S, Das KK. Socio-economic and demographic determinants of childhood anemia. J Pediatr (Rio J). 2015; 91 (5): 471-477. doi: 10.1016/j.jped.2014.09.009.

[18] Gebreweld A, Ali N, Ali R, Fisha T. Prevalence of anemia and its associated factors among children under five years of age attending at Guguftu health center, South Wollo, Northeast Ethiopia. PLoS One. 2019; 14 (7): 1-13. doi: 10.1371/journal.pone.0218961.

[19] Kuziga F, Adoke Y, Wanyenze RK. Prevalence and factors associated with anaemia among children aged 6 to 59 months in Namutumba district, Uganda: A cross- sectional study. BMC Pediatr. 2017; 17 (1): 1-9. doi: 10.1186/s12887-017-0782-3.

[20] Leite MS, Cardoso AM, Coimbra CE, et al. Prevalence of anemia and associated factors among indigenous children in Brazil: Results from the First National Survey of Indigenous People's Health and Nutrition. Nutr J. 2013; 12 (1): 1-11. doi: 10.1186/1475-2891-12-69.

[21] Parbey PA, Tarkang E, Manu E, et al. Risk Factors of Anaemia among Children under Five Years in the Hohoe Municipality, Ghana: A Case Control Study. Anemia. 2019; 2019. doi: $10.1155 / 2019 / 2139717$. 
[22] Magalhães RJS, Clements ACA. Mapping the risk of anaemia in preschool-age children: The contribution of malnutrition, malaria, and helminth infections in West Africa. PLoS Med. 2011; 8 (6). doi: 10.1371/journal.pmed.1000438.

[23] Kejo D, Petrucka P, Martin H, Kimanya M, Mosha T. Prevalence and predictors of anemia among children under 5 years of age in Arusha District, Tanzania. Pediatr Heal Med Ther. 2018; Volume 9: 9-15. doi: 10.2147/phmt.s148515.

[24] Kisiangani I, Mbakaya C, Makokha A. Prevalence of Anaemia and Associated Factors Among Preschool Children ( 6-59 Months) in Western Province, Kenya. Public Heal Prev Med. 2015; 1 (1): 28-32.

[25] Kumari S, Garg N, Kumar A, et al. Maternal and severe anaemia in delivering women is associated with risk of preterm and low birth weight: A cross sectional study from Jharkhand, India. One Heal. 2019; 8 (February): 100098. doi: 10.1016/j.onehlt.2019.100098.

\section{Biography}

Mohammad Moniruzzaman Mollah, MBBS, DCH (PhD Fellow (IBSc, Rajshahi University), Assistant Professor, Department of Paediatrics, Shaheed Ziaur Rahman Medical College, Bogura, Bangladesh; Prof. Dr. Ashik Mosaddik PhD, Professor and Chairman, Department of Pharmacy, University of Rajshahi, Rajshahi; Dr. Asgor Hossain, MBBS, FCPS. Associate Prof. (Rtd.), Department of Paediatrics, Rajshahi Medical College, Rajshahi, Bangladesh; Dr. Andrew Asim Roy (PhD, MBBS, MSc, MPH) Faculty and Researcher, Department of Medicine and Biomedical Sciences, Maastricht University, the Netherlands; Dr. Sultana Naznin MBBS, DGO, Resident Surgeon, Department of Gynae and Obs, IBMCH, Rajshahi, Bangladesh; Dr. Md. Shukur Ali, PhD, Assistant Professor, Department of English, University of Development Alternative (UODA) Dhaka, Bangladesh, Prof. Dr. Parvez Hassan PhD, IBSc, Rajshahi University, Rajshahi, Bangladesh. 